\title{
The translation of the Vertigo Symptom Scale into Afrikaans: A pilot study
}

\author{
Christine Rogers \\ Jacques de Wet \\ Ayanda Gina \\ Ladine Louw \\ Musa Makhoba \\ Lee Tacon \\ Division of Communication Sciences and Disorders, Department of Health and Rehabilitation Sciences, University of Cape Town \\ Correspondence to: C Rogers (Christine.Rogers@uct.ac.za)
}

\begin{abstract}
Dizziness is a common clinical problem that is challenging to diagnose and treat. One of a subset of symptoms that fall under the encompassing term of dizziness is vertigo, which is the subjective experience of hallucination of movement, often associated with vestibular disorders. While dizziness has a broad range of causes, the association between vestibular disturbance, and its attendant vertigo, and anxiety is well established. The Vertigo Symptom Scale (VSS) is a questionnaire that assesses aspects of vertigo and vertigo-related anxiety. The aim of this study was twofold. In phase 1, a translation of the VSS into Afrikaans was evaluated using the Delphi consensus technique and two panels of participants. Panel 1 comprised first-language Afrikaans speakers who commented on the language, grammar and vocabulary of the items. Panel 2 were bilingual health care practitioners with either a psychology background or a special interest in vertigo. After two rounds of consultation, consensus was achieved and the final translation of the Afrikaans Vertigo Symptom Scale (AVSS) was agreed upon, as well as a list of Afrikaans words descriptive of vertigo. Phase 2 used a descriptive, correlational design. The aim was to pilot the AVSS with a sample of vertiginous and control participants to establish its ability to differentiate between the two groups and to explore experiences of vertigo and anxiety within the two embedded subscales. The results of the pilot study yielded significant statistical differences $(p<0.001)$ between the groups on both subscales of the tool. Preliminary results suggest that the AVSS is able to identify patients with vertiginous disturbance and anxiety. The AVSS presents with good sensitivity and specificity as measured by the receiver-operating characteristic (ROC) curve.
\end{abstract}

Afrikaans is the home language of almost 6 million people in South Africa. The translation of the VSS into Afrikaans presents health care professionals with a tool with which to assess vertigo and vertigo-related anxiety in this population.

Keywords: Afrikaans, anxiety, Delphi, dizziness, vertigo, Vertigo Symptom Scale, vestibular disorders

Diagnosis and management of dizziness is challenging and often a source of frustration for the clinician (Kerr, 2005). Reasons for this difficulty include the subjective nature of the complaints, issues that patients have when trying to describe symptoms, and the broad range of causes, ranging from vestibular to psychological, which could be responsible for the presence of symptoms. Dizziness is a general term often used by patients to describe a variety of sensations, which include lightheadedness, presyncope and other experiences including vertigo. Vertigo is a perception of motion when there is no external source for that sensation (Yardley, Luxon \& Haacke, 1994), and is classically associated with vestibular disorders. Vertigo may be viewed as a distinct clinical entity along a continuum of symptoms that are broadly described as dizziness. The identification of the presence of vertigo, and its association with vestibular dysfunction, may direct professionals such as otologists and audiologists in their choice of investigations, management and subsequent referrals. For example, it would be mandatory to conduct an audiological assessment in cases of vertigo, while dizziness related to presyncope or cardiac causes would not necessitate such tests. Although an appreciation of the difference between dizziness and vertigo is critical for effective diagnosis and treatment, the two terms are often used interchangeably and are confused by both patients and clinicians (McPherson \& Whitaker, 2001).

Attacks of vertigo may be distressing because of the associated autonomic and vegetative symptoms (Mégnigbêto, Sauvage \& Launois, 2001). In addition, vertiginous episodes have been associated with anxiety, panic and social phobia (Aslan, Ceylan, Kemaloglu \& Goksu, 2003; Tschan et al., 2008; Wiltink et al., 2009). There is increasing evidence of an association between vestibular disorders and activation of areas of the brain concerned with emotion, and in turn with the autonomic nervous system (Best et al., 2006; Meli, Zimatore, Badaracco, De Angelis \& Tufarelli, 2007; Wiltink et al., 2009). An additional concern regarding the psychological sequelae of vestibular syndromes is that negative or maladaptive coping mechanisms, which include avoidance of stimulation, may reduce compliance with vestibular rehabilitation therapy and ultimately delay recovery (Aslan et al., 2003; Cohen \& Kimball, 2003; Luxon, 2004; Meli et al., 2007). It is therefore suggested that the dual elements of vestibular symptoms and potential psychological involvement are investigated in all patients who present with vertigo.

A detailed, systematic and holistic case history, conducted with insight and an empathic manner, is crucial in every case and most likely to result in a diagnosis of the cause of vertigo (Bennett, 2008). Reliance on sophisticated clinical or laboratory testing in place of, or as an adjunct to, the case history will seldom return a useful diagnosis; indeed, it is the exception that results of formal vestibular tests would influence, or change, management decisions (Shepard, 2007). While an accurate case history is essential for effective treatment, anamnesis may be more problematic when there are linguistic and cultural differences between the health care professional and patient, a scenario common in a diverse country such as South Africa.

A variety of questionnaires have been used in clinical practice in order to identify or assess vertigo symptoms or handicap, as well as related issues such as anxiety. One advantage of questionnaires is to focus patients' thoughts on their complaints prior to the consultation, allowing the clinician to highlight relevant issues. Questionnaires may be used as an entrée to explore areas that may otherwise be difficult to address, for example, probing symptoms of panic or anxiety may elicit a guarded or defensive response. Skilfully selected questionnaires add to the completeness of the case history, and results may signal the need for further investigations or referrals. One such questionnaire, the Vertigo Symptom Scale (VSS) (Yardley, Masson, Verschuur, Haacke, \& Luxon, 
1992), has two embedded subscales; one evaluates vertigo severity and the explores symptoms of somatic anxiety. It was developed after extensive interviews which explored the experience of patients living with vertigo. Results from the VSS were correlated with independent scales of anxiety and vertigo handicap, as well as diagnostic classification systems and objective testing. The resulting VSS has been researched extensively and good reliability and concurrent validity have been established (Yardley et al., 1992). The VSS is the self-assessment scale targeting vestibular symptoms most used in clinical practice (Faag, Bergenius, Forsberg \& Langius-Eklöf, 2007). It has been translated into a number of languages without losing validity (Tschan et al., 2008).

\section{The South African context}

In South Africa, almost 6 million people use Afrikaans as their home language, making it the third most common language spoken. A further 15 million people are proficient in Afrikaans (South Africa Info, 2001). In the Western Cape, where this study was conducted, the majority (55.3\%) of the population speak Afrikaans (Statistics South Africa, 2004). English language questionnaires exploring health-related quality of life, functional assessments of chronic illness therapy and measures of mental health have been translated into Afrikaans using a variety of methods (Jelsma \& Ferguson, 2004; Harpham et al., 2003; Webster, Cella \& Yost, 2003). Efforts have been made to translate audiological materials, such as stimuli for speech recognition, into Zulu (Panday, Kathard, Pillay \& Govender, 2007). While many English language questionnaires are available for exploring aspects of dizziness and vertigo, to the authors' knowledge none has been translated into other languages spoken in South Africa. At present there are no questionnaires available in Afrikaans with which to explore the experience of symptoms of vertiginous patients presenting to health care services. Given the large numbers of Afrikaans speakers nationally and their predominance in the Western Cape, a self-assessment scale was selected for translation and validation. The VSS was selected for this research because of its ability to explore vertiginous symptoms and those of anxiety and panic simultaneously.

\section{Delphi consensus procedure}

The Delphi consensus procedure is a method often used in healthrelated research and involves obtaining consensus of opinion from knowledgeable participants through the use of structured questioning in a series of rounds (Hasson, Keeney, \& McKenna, 2000). Results from the first round of questions are relayed back to participants in subsequent rounds (De Villiers, de Villiers \& Kent, 2005) and in this study suggestions of Afrikaans words that would capture the essence of the word vertigo were also sought. Delphi procedures are costeffective methods of gathering information, and in contrast to focus groups, participants are not in contact with each other, or aware of the identities of other panel members (Hardy et al., 2004; Powell, 2002). Use of Delphi consensus procedures in audiology is ongoing, with panels currently employing this method to aid the development of International Classification of Functioning (ICF) health core sets for hearing loss (Danermark et al., 2010) and vertigo (Podlipny, personal communication, 10 October 2010).

The aims of this study were to validate a translation of the VSS (Yardley et al., 1992) into Afrikaans, and to conduct a pilot study of the translation's ability to differentiate between participants with and without complaints of vertigo. The study was conducted in two phases, which will be presented in the 'Method' section.

\section{Method}

\section{Study design}

In phase 1, a Delphi consensus procedure was used first, to gain agreement on the translation of the VSS from two panels of participants. Panel 1 comprised first-language Afrikaans speakers, who commented on grammar and vocabulary used. Panel 2 were bilingual health care professionals who had experience in treating patients with vestibular disorders. In addition both panels were asked to contribute Afrikaans words that captured the essence of the experience of vertigo. In phase 2, a descriptive, correlational design was used and the Afrikaans Vertigo
Symptom Scale (AVSS) was piloted among a sample of participants with and without vertigo.

\section{Phase 1: translation of the VSS and Delphi consensus procedure}

The VSS was translated from English into Afrikaans using the steps depicted in the flow chart (Figure 1). The Delphi procedure was used to obtain consensus on the translation. Conventional Delphi designs have four rounds, but this was modified to two rounds as consensus was only sought on the translation of a pre-exisiting, validated scale.

\begin{tabular}{|c|}
\hline \multicolumn{2}{|c|}{ Step 1: translation of the English Vertigo Symptom Scale } \\
\hline Researcher 1 translated into Afrikaans \\
\hline Step 2: individual translations merged into single translation \\
\hline Bilingual individual not involved in step 1 provided translation back into English \\
\hline Step 3: back translation compared to English Vertigo Symptom Scale \\
\hline No charges made as versions were suffciently similar. \\
\hline
\end{tabular}

Fig. 1. Flow chart depicting the translation of the Vertigo Symptom Scale into Afrikaans.

\section{Phase 1 participants}

Two panels were selected through purposive sampling. Panel 1 consisted of 5 first-language Afrikaans-speaking lay participants, and panel 2 comprised 5 bilingual health care practitioners from a variety of disciplines, including otolaryngology, audiology, psychology and aviation medicine, who regularly treated patients with vertigo. All except the psychologist had received specialised training in vestibular disorders and were familiar with the VSS.

\section{Phase 1 materials and procedures - Delphi consensus rounds 1 and 2}

Panel 1 answered a list of questions on the language, grammar and vocabulary of items in the translated VSS. As the scale was to be directed at patients, the translation needed to be comprehensible to lay individuals. Questions for panel 2 centred on the applicability of items to the Afrikaans patient population to which practitioners were exposed, as well as to verify the use of vocabulary chosen to explain terms such as 'giddy'. Panel 2 was also polled with regard to words commonly used by their patients to describe the experience of vertigo. Both panels were consulted regarding the Afrikaans translation and equivalence with the English original. Panelists selected answers from a 5-point Likert scale ranging from 'strongly agree' to 'strongly disagree'; in addition qualitative comments were invited. Examples of questions asked of the panels are indicated in Box 1 below.

\section{- A patient who reads 'swewing' will make the association with a feeling of 'swimming, floating or soaring' (item 7). \\ - Do you think that 'dofheid' encompasses the essence of visual 'blurring' (item 13)?}

Box 1. Example of questions posed to the panellists participating in the Delph consensus procedure, round 1 .

There is a lack of agreement in the literature as to what percentage is acceptable as consensus, with values ranging from $55 \%$ to $100 \%$ (Powell, 2002). An 80\% majority was chosen as it represented a robust majority leaving less room for errors (Hardy et al., 2004). When $80 \%$ consensus was achieved no changes were made to the initial translation. Round 2 of the Delphi consensus addressed items from round 1 upon which consensus had not been achieved. Panel members were able to re-evaluate their opinion based on the responses and suggestions from both panels that were presented verbatim (Greatorex \& Dexter, 2000). Respondents had to 'agree' or 'disagree' with each item. For round 2 a 
majority consensus of $\geq 51 \%$ finalised the changes. An example of one of the questions from round 2 appears in Box 2. The results of the Delphi consensus are the AVSS (Appendix 1), and a list of Afrikaans words used to describe the subjective experience of vertigo (see Box 3 in the 'Results' section).

For item 4, both panel 1 and panel 2 agreed by majority that 'neerval' is an appropriate translation for 'fall. However, other suggestions were made. Choose the item that you most agree with.

$\begin{array}{lll}\text { Do you agree with } & \text { a) 'neerval' } & \text { Agree/ Disagree } \\ \text { Or the suggestion } & \text { b) 'omval' } & \text { Agree/ Disagree }\end{array}$

Box 2. Example of questions posed to the panellists participating in the Delphi consensus procedure, round 2.

\section{Phase 2: pilot study of the AVSS}

Phase 2 piloted the AVSS and used descriptive correlational statistics to analyse the results. There were two aims for phase 2: first, to assess and describe the relationship between the participants' presenting symptoms and their scores on the AVSS for the anxiety and vertigo subscales; and second, to demonstrate whether the AVSS could discriminate between vertiginious and control participants.

\section{Phase 2 participants}

As both a non-vertiginous group and group of participants with vertigo were sought, all adult patients attending ENT outpatient services were asked if they were interested in enrolling in the research study. Phase 2 participants who reported that their first language was Afrikaans and who were capable of completing the AVSS unassisted were selected using a purposive non-randomised sampling method. The Delphi consensus procedure generated key terms used to describe vertigo (see Box 3 ), and symptoms reported by participants within the last 3 months had to match one or more of these terms for participant inclusion in the vertiginous group; control subjects reported no vertigo within the same period.

Eighty-five patients gave consent; subsequently 13 were excluded because the questionnaire was returned incomplete. The sample consisted of 72 participants, of whom 50 were female. Vertigo was present in 41 participants and 31 were controls. The age of participants with vertigo ranged from 20 to 82 years (mean 49 years), and that of the controls from 27 to 81 years (mean 45 years). The median schooling level was grade 10 , mode of grade $12(N=72)$.

\section{Ethical clearance}

The research protocol was designed in accordance with the Declaration of Helsinki (World Medical Association, 2008). Ethical clearance was obtained from the institution's Human Research Ethics Committee as well as from the two hospitals at which data were collected. Informed consent was obtained from all participants for both phases of the study. Professor Lucy Yardley granted permission for the use of the VSS, its translation and naming as the Afrikaans Vertigo Symptom Scale (Yardley, personal communication, January 2009).

\section{Phase 2 materials and procedures}

Once informed consent was obtained, participants completed the screening questionnaire assessing the main reason for the visit: presence of previous and current symptoms of vertigo, panic, anxiety, depression and medication use. The AVSS was completed and participants were divided into vertiginous and control groups based on the results of the screening questionnaire.

\section{Statistical analysis}

The diagnosis was recorded from the hospital folder. Data were initially entered into Microsoft Office Excel 2007 (v. 12.0.6300.5000). Data from $10 \%$ of the sample were re-analysed at random to check for reliability of data capturing. The Statistica (v. 8) package and Statistical Package for Social Sciences (SPSS) (v. 15) were used for statistical analysis. Cronbach's alpha assessed internal consistency. The McNemar test determined the classification congruence between the participants' presenting complaint of vertigo, or the lack thereof, and their diagnosis. The adjusted $t$-test and Mann-Whitney $U$ were conducted. The receiveroperating characteristic (ROC) curve was used as a visual index of the accuracy of the AVSS and analysed sensitivity and specificity.

\section{Results}

\section{Phase 1}

The researchers who performed the initial translations found that the two independent preliminary translations were very similar. Furthermore, no substantial differences were found when the initial forward and back translations were compared. In round 1, the first-language Afrikaans panel reached consensus on 22 of 31 items. The health care professional panel agreed on 22 of 32 questions. Round 2 consisted of 21 questions, 19 of which had suggestions included. Consensus was achieved for all of the 21 questions in round 2 and the AVSS was finalised. Participants mentioned that the layout of the AVSS made it challenging to complete, so the format (but not the content) was reworked to make it more accessible. For example, response options were arranged in boxes for participants to tick or circle. The terms suggested by the panellists for Afrikaans synonyms for vertigo appear in Box 3.

- Rondomtalie, tuimel, bollemakiesie, mallemeule, tol

- 'Draai' (patient or the environment)

- Draaiduiseligheid

- Dronk/kop-dronkheid

- 'Ek beweeg hierdie kant toe, die wêreld anderkant toe.'

Box 3. Words and terms that were obtained from qualitative feedback in round 1 of the Delphi technique describing the symptom of vertigo.

\section{Phase 2}

The VSS evaluates two areas - the experience of vertigo, dizziness and imbalance (VER subscale) and symptoms of anxiety and related psychological problems, the Anxiety and Autonomic Symptom Scale (AA subscale). Cronbach's alpha indicated good internal consistency on the VER subscale $(\alpha=0.8822)$ and the AA subscale $(\alpha=0.9248)$, i.e. the results obtained on the two subscales indicated that the scale will elicit consistent results, rather than results obtained by subject or item variance. The McNemar test was used to analyse the classification congruence between complaints of vertigo and the expectation of the symptom based on the diagnosis recorded in the hospital notes. Four of the 72 participants included in the final analysis (those with complete AVSS scores) were incorrectly categorised as having vertigo when in fact they did not. The McNemar test $(0.98 ; p=0.3211)$ found no significant difference between the participants' complaint of vertigo and the expectation of the symptom based on diagnosis. This minimal difference in classification indicated good categorisation of vertiginous participants and controls, based on participants' presenting complaints. For the vertiginous participants the score of symptoms of dizziness, vertigo or imbalance was relatively high, with the VER subscale showing mean 19.902, standard deviation (SD) 12.047, $N=41$, where the highest possible score obtainable on the VER is 76. Most of the vertiginous sample (54\%) scored on all three features of dizziness: a feeling of spinning or moving around, being light-headed, swimmy or giddy, and a feeling of unsteadiness (items 1, 7 and 18 on the AVSS). In contrast, no participant from the control group reported all three classic features of dizziness with increased occurrence (scores of 3 or 4 on the AVSS). The control sample yielded a significantly lower mean score overall, with the VER subscale showing mean 3.742, SD 3.838, $N=31$. This would suggest that the VER is able to differentiate reliably between those with and without vertigo. Figure 2 shows histograms of the VER data for both samples.

In addition to the presence of symptoms of dizziness, over one-third of the vertiginous sample complained of symptoms of autonomic nervous system arousal and/or anxiety; checking items such as the presence 


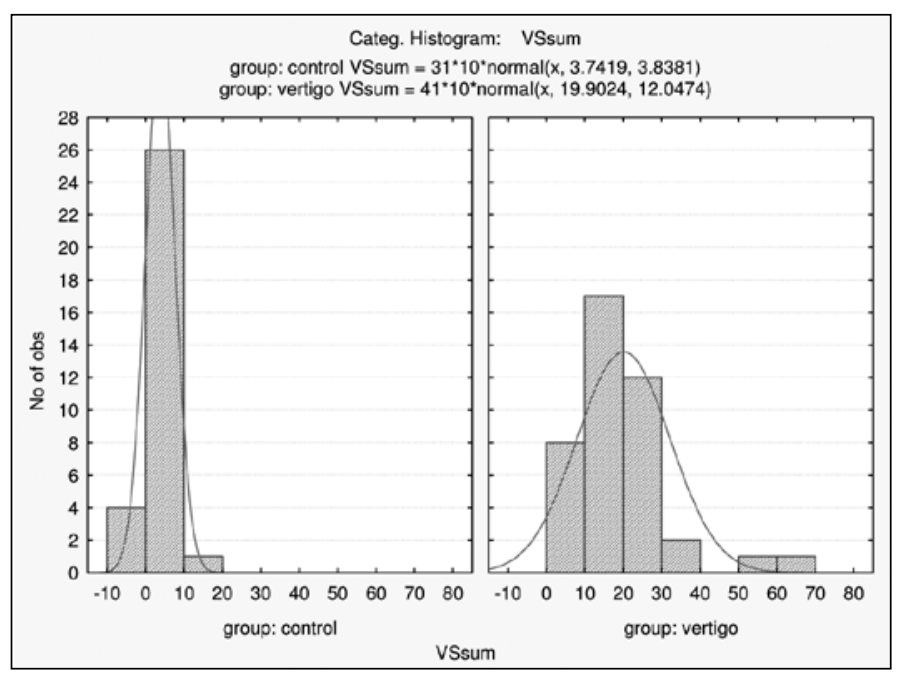

Fig. 2. Histograms depicting the spread of scores obtained on the VER subscale. The control results are in the left diagram. Scores on the VER are found on the $x$-axis with the number of participants found on the y-axis. Note that the control sample's scores are substantially lower than those obtained by the vertiginous sample.

of hot or cold spells, heart palpitations, and presyncope (items 3, 10 and 22). A relatively high mean score overall for the AA subscale was obtained (mean 26.829, SD 16.269, $N=41$ ), where the highest possible score on this subscale is 60 . The control group reflected a lower overall mean score, with the following obtained: mean 13.065, SD 9.284, $N=31$. Interestingly, none of the participants in the control group reported presyncope. Figure 3 shows histograms of the scores obtained on the AA for both samples.

Successful differentiation between the participant groups was therefore obtained on both subscales of the AVSS. Further statistical analysis was conducted, and both the parametric and non-parametric measures used indicated significant statistical differences on both subscales between the samples with $t$-test and Mann-Whitney $U$ values less than $p=0.05$. Between both samples, the following results were obtained on the adjusted $t$-test and Mann-Whitney $U$ non-parametric analysis: VER [ $t$ (50.25) $=-8.065, p<0.001$; Mann-Whitney $U(49)=0.000, p<0.001]$ and AA: $[t(65.64)=-4.529, p<0.001$; Mann-Whitney $U(316.5)=0.000$, $p<0.001]$. The $p$-scores obtained for the $t$-test and Mann-Whitney $\mathrm{U}$ are substantially less than 0.001 , which is less than the set criteria for statistical significance, increasing the significance of the results obtained.

An ROC curve (Figure 4) was constructed in an attempt to establish cut-off scores that would distinguish between cases of vertigo and

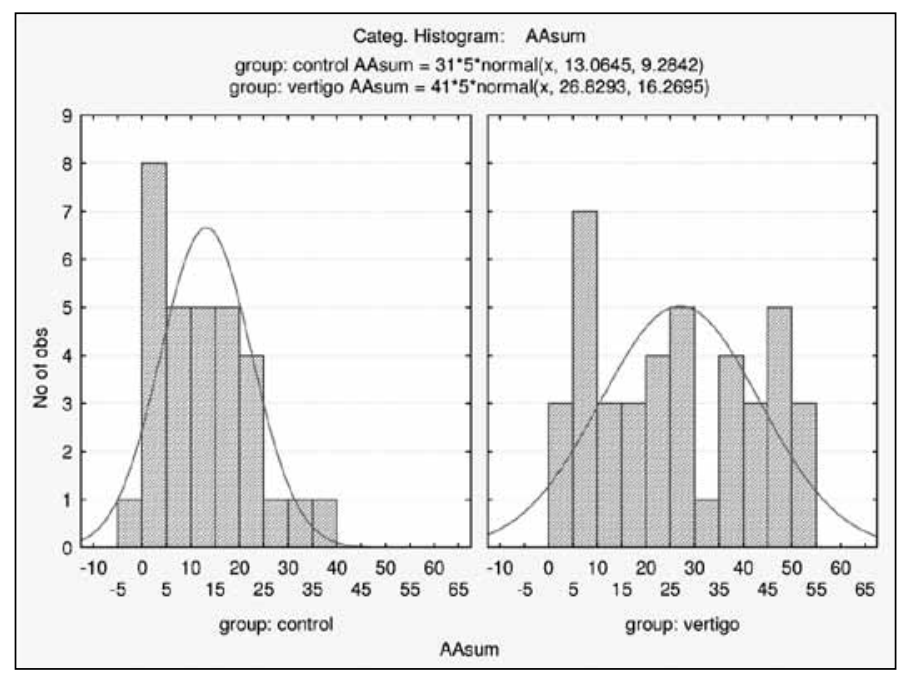

Fig. 3. Histograms depicting the spread of scores obtained on the AA subscale. Scores for the control group are displayed in the left diagram. Scores obtained on the $A A$ are found on the $x$-axis. Overall, the vertiginous sample scored higher on the $A A$.

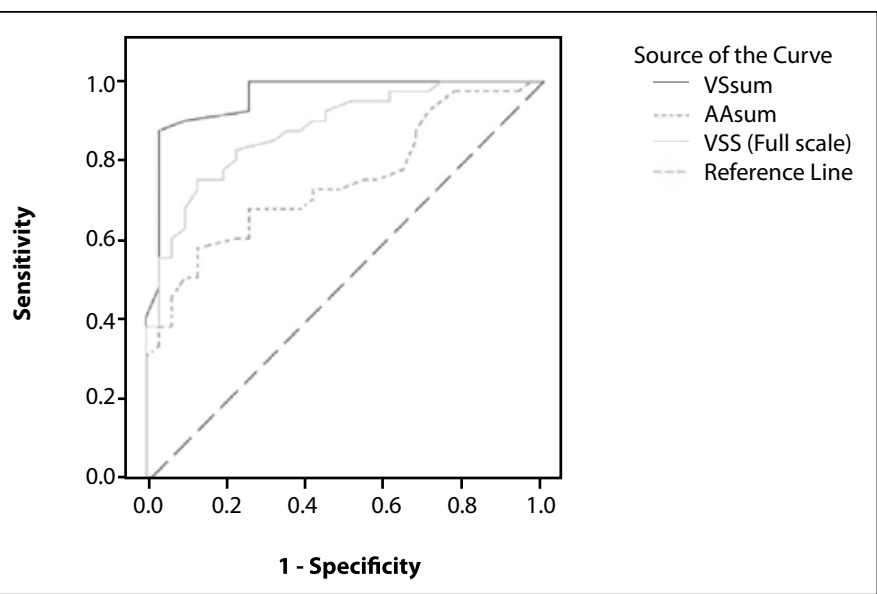

Fig. 4. The ROC curve obtained for the AVSS, including both the VER and AA subscales.

non-cases. The AVSS shows good sensitivity and specificity for both subscales and as a whole. The VER has better sensitivity in identifying vertiginous versus control participants than the AA's ability to identify those with anxiety from those without. The VER has an optimal cutoff suggested at 7.5, which yields a sensitivity of 0.902 and specificity of 0.097 . The AA did not indicate an optimal cut-off and 17.5 was suggested, as the best balance for sensitivity is 0.683 and specificity is 0.258 at this level. To conclude, the entire AVSS presents with relatively good sensitivity and specificity (demonstrated by the second line from the reference line on the ROC).

\section{Discussion}

There are various methods of evaluating the translation of an instrument, ranging from simple forward- and back-translations to subjecting the translation to a process of review using a technique such as the Delphi. In this study a Delphi consensus procedure, using panels of first-language Afrikaans speakers and bilingual health care professionals, yielded the AVSS which was piloted with vertiginous and control participants. Although the focus of the discussion is on the results of the pilot study, the Delphi is discussed briefly. Delphi consensus procedures have a number of features that may either enrich or weaken a study. They are cost-effective, and panel members are usually selected for their strengths and are not unduly influenced by each other. However, a lack of standardisation in the method, including decisions about when consensus has been reached, lack of test-retest reliability and possible selection bias (Hasson et al., 2000), all warrant concern. Although there is no agreement on what to accept as consensus in the literature (Hasson et al., 2000), a conservative figure was chosen for consensus in the first round, favouring caution. In the second round, consensus was achieved for all items. There were limitations in terms of the small number of participants on each panel. It is possible that the panels' opinions were not representative of a wider first-language or expert population, raising the possibility of selection bias. In addition, the use of a first-language lay panel could be queried with regard to their value; however, it was felt that the final translation should be accessible in terms of vocabulary to a projected patient population, and that the lay panel would bring a different perspective to that of the health care professionals. Furthermore, no formal tests to establish language competence of any of the participants were conducted. Although the limitations of the Delphi consensus procedure require acknowledgement, they are somewhat ameliorated by its use only to confirm a translation of an already validated questionnaire. The researchers believe that concurrent validity has been established as a result of the AVSS's ability to discriminate between individuals presenting with and without vertigo. Furthermore, Cronbach's alpha suggested internal consistency within the scale.

\section{Clinical utility of the AVSS}

Because of the array of symptoms and aetiologies with which a vertiginous patient may present, the underpinning of a competent assessment is a thorough case history (Mégnigbêto et al., 2001; Yardley 
et al., 1992). However, in South Africa clinicians may encounter challenges in obtaining a case history as a result of linguistic issues. A questionnaire such as the AVSS explores symptoms of dizziness and vertigo, associated autonomic nervous system symptoms and anxiety-related factors. The AVSS has proven reliable and could be useful for clinicians to categorise patients' subtypes of dizziness. It bears reiteration that precise symptom definition, plus identification of associated symptoms such as anxiety, is essential for effective diagnosis. Further, self-assessment scales require patients to be reflective about their complaint. As the AVSS covers a wide range of symptoms, the patient is asked to consider several aspects of his/her condition. The AVSS may create an opportunity for the clinician to explore specific areas, which may assist in keeping the consultation focused and timeefficient. For example, identification of anxiety is essential for successful management (Luxon, 2004), and high scores on the AA subscale would alert the clinician to explore this during the clinical encounter and refer the patient if necessary. Even when physical symptoms cannot be controlled optimally, such as in the case of Ménière's disease, recognition and management of psychological distress can result in improvements in the quality of life (Kirby \& Yardley, 2008).

Significant statistical differences were found between the samples for both subscales embedded in the AVSS. The ROC curve suggested that the AVSS is sensitive and specific in correctly identifying true cases of participants complaining of vertigo. However, a clinical tool may have considerable power in identifying those patients whom it aims to identify, yet be of little value when it comes to patient care (Zwieg \& Campbell, 1993). As one of the primary concerns in management of vertigo is delineating its true nature, which in turn will dictate subsequent treatment and referral options, instruments with a high hit rate are desirable. The AVSS could be used at various levels of care and ensure that patients are referred to the appropriate health care professional - in this case vertiginous patients to audiologists and otologists.

In spite of the AVSS being statistically robust, it is apparent that not all tools are suitable for all patients. In this study, 13 participants were excluded because the AVSS had not been completed in full. Qualitative feedback from these individuals suggested that some had difficulty with the format, which followed the published English version. This resulted in a new layout for the scale, with boxes for participants to enter their responses, which had a clearer appearance. However, when the challenges of a self-assessment scale in cases where literacy may be an issue are considered, the AVSS in its present format may still be too daunting for some patients. For individuals with low general literacy levels faced with material presented in a different language, written documents used in health care may give rise to frustration. Interestingly, clinicians are thought to overestimate their patients' literacy skills, leading to more difficulties (Schmidt von Wühlisch \& Pascoe, 2010). It is possible that the AVSS may not be of practical use in some clinical settings, depending on the functional and health literacy of the patient population. The study did not explore the threat to validity should the scale be administered by a health care professional rather than selfadministered, but this could be investigated at a later stage.

The generalisability of the study is limited by the size and centralised nature of the sample. Study data cannot account for the range of dizzy patients who could potentially consult a clinician. The state hospitals were both located in an urban centre and it is possible that rural participants may have yielded substantially different results. In addition participants did not undergo objective testing, thus limiting the correlation between the participants' diagnosis and their presenting complaint of vertigo, or lack thereof. However, a counter-argument to this is that objective testing often does not prove a diagnosis or even the presence of a patient's symptoms (Kerr, 2005; Mendel, Bergenius \& Langius, 1999). It is possible that a Hawthorne effect exists. Participants may have reported more symptoms, or more severe symptoms, on the AVSS in the hope that they might receive preferential treatment or have their medical needs given more priority. However, it was pointed out to each potential participant that the researchers would neither assess nor manage patients' conditions and that this would be attended to by the regular staff.

As this was a pilot study, future research should include a larger sample of participants, from a variety of settings. Furthermore, as there is no other suitable Afrikaans questionnaire with which to compare the AVSS, construct validity was not evaluated. It is therefore recommended that another scale such as the Dizziness Handicap Inventory (DHI) (Jacobson \& Newman, 1990) be translated and piloted. The results of the two scales could be compared for information regarding the validity of the AVSS. Furthermore, the results of the self-assessment scales could be correlated with findings on clinical or objective examination.

In South Africa, a range of clinicians may be involved in the management of patients with vestibular involvement, including otolaryngologists, neurologists, audiologists with vestibular training, physiotherapists and psychologists. All of these professionals will approach the vertiginous patient from a different perspective relative to their training. The study revealed that there does not appear to be an Afrikaans word that appropriately implies the symptom of vertigo, so 'draaiduiseligheid' is suggested as suitable for use within clinical settings. The term adequately conveys a sense of dizziness or of being light-headed, while incorporating the vital aspect of a hallucination of movement. Consistent use of terminology within and between disciplines, as well as use of the AVSS, may offer something to bridge professional differences and aid the clinician who is not specialised in the area of vestibular disorders. Clinical reasoning regarding both the definition of the presenting symptoms and the results from the subscales of the AVSS may in turn make referrals more rational and appropriate.

\section{Conclusion}

The AVSS is able to detect classic symptoms of vertiginous distress, which often include associated symptoms of autonomic nervous system arousal. The ROC measure indicated that the AVSS presents with good sensitivity and specificity, and therefore demonstrates good discriminative ability in identifying patients with vertigo. Hence it is an ideal first option in patient self-assessment and can appropriately confirm the presence of symptoms, explore facets of anxiety and direct appropriate management and future referrals. The AVSS will complement the case history, which in turn will support more accurate diagnosis. It should be noted that the English and translated VSS were designed as self-assessment scales, and this could render them inaccessible for a sizeable proportion of the population who do not have functional literacy. The word 'draaiduiseligheid' is a useful addition to the clinical armamentarium as it captures a description of movement and disorientation to the environment. As symptom definition is a fundamental first step in discriminating between dizziness and vertigo, and thus directing assessment and management decisions, it is hoped that this will prove to be a useful contribution. Considering the wide use of the VSS around the world in specialist clinics, the AVSS has the potential to enhance the assessment of vertigo and attendant vertigorelated anxiety in the Afrikaans-speaking population.

Acknowledgements. The researchers would like to extend their gratitude to Professor Lucy Yardley for permission to use and translate the VSS, and Ms Anneli Hardy for her statistical analysis. We also wish to acknowledge the contribution of the panellists and the participants at the two institutions at which the study was conducted, and the two anonymous reviewers for their constructive comments.

\section{References}

Aslan, S., Ceylan, A., Kemaloglu, Y.K., \& Goksu, N. (2003). Validity and reliability of the Turkish version of the Vertigo Handicap Questionnaire (VHQ) in a group of patients with vertigo. Gazi Medical Journal, 14, 167-173.

Bennett, M. (2008). The vertigo case history. In G.P. Jacobson \& N.T. Shepard (Eds.). Balance function assessment and management (pp. 45-62). San Diego: Plural Publishing.

Best, C., Eckhardt-Henn, A., Diener, G., Bense, S., Breuer, P., \& Dieterich, M. (2006). Interaction of somatoform and vestibular disorders. Journal of Neurology, Neurosurgery \& Psychiatry, 77, 658-664.

Cohen, H.S., \& Kimball, K.T. (2003). Increased independence and decreased vertigo after vestibular rehabilitation. Otolaryngology - Head and Neck Surgery, 128, 60-70.

Danermark, B., Cieza, A., Gange, J-P., Gimigliano, F., Granberg, S., Hickson, L., et al. (2010). International classification of functioning, disability and health core sets for hearing loss: A discussion paper and invitation. International Journal of Audiology, 49, 256-262. 
De Villiers, M.R., De Villiers, P.J.T., \& Kent, A.P. (2005). The Delphi technique in health science education research. Medical Teacher, 27, 639-643.

Faag, C., Bergenius, J., Forsberg, C., \& Langius-Eklöf, A. (2007). Symptoms experienced by patients with peripheral vestibular disorders: evaluation of the Vertigo Symptom Scale for clinical application. Clinical Otolaryngology \& Allied Sciences, 32, 440-446.

Greatorex, J., \& Dexter, T. (2000). An accessible analytical approach for investigating what happens between the rounds of a Delphi study. Journal of Advanced Nursing, 32, 1016-1024.

Hardy, D.J., O'Brien, A.P., Gaskin, C.J., O’Brien, A.J., Morrison-Ngatai, E., Skews, G., et al. (2004). Practica implication of the Delphi technique in a bicultural mental health nursing study in New Zealand. Journal of Advanced Nursing, 46, 95-109.

Harpham, T., Reichenheim, M., Oser, R., Thomas, E., Hamid, N., Jaswal, S., et al. (2003). How to do (or not to do). Measuring mental health in a cost-effective manner. Health Policy and Planning 18, 344-349.

Hasson, F., Keeney, S., \& McKenna, H. (2000). Research guidelines for Delphi survey technique. Journal of Advanced Nursing, 32, 1008-1015.

Jacobson, G.P., \& Newman, C.W. (1990). The development of the Dizziness Handicap Inventory. Archives of Otolaryngology - Head \& Neck Surgery, 116, 424-427.

Jelsma, J., \& Ferguson, G. (2004). The determinants of self-reported health-related quality of life in a culturally and socially diverse South African community. Bulletin of the World Health Organisation, $82,206-212$.

Kerr, A.G. (2005). Assessment of vertigo. Annals of the Academy of Medicine of Singapore, 34, 285-288.

Kirby, S.E., \& Yardley, L. (2008). Understanding psychological distress in Ménière’s disease: a systematic review. Psychology, Health \& Medicine, 13, 257-273.

Luxon, L.M. (2004). Evaluation and management of the dizzy patient. Journal of Neurology, Neurosurgery \& Neuropsychiatry, 75, 45-52

McPherson, D.L., \& Whitaker, S.R. (2001). Dxx: disequilibrium and aging. In J.A. Goebel (Ed.). Practical management of the dizzy patient (pp. 269-297). Philadelphia: Lippincott Williams \& Wilkins.

Mégnigbêto, C.A., Sauvage, J., \& Launois, R. (2001). Validation clinique d'une échelle du vertige: European Evaluation of Vertigo Scale (EEV): a clinical validation study. Revue Laryngology Otology \& Rhinology, $122,95-102$.

Meli, A., Zimatore, G., Badaracco, C., de Angelis, E., \& Tufarelli, D. (2007). Effects of vestibular rehabilitation therapy on emotional aspects in chronic vestibular patients. Journal of Psychosomatic Research, 63, 185-190.

Mendel, B., Bergenius, J., \& Langius, A. (1999). Dizziness symptom severity and impact on daily living as perceived by patients suffering from peripheral vestibular disorder. Clinical Otolaryngology \& Allied Sciences, 24, 286-293.
Panday, S., Kathard, H., Pillay, M., \& Govender, C. (2007). Development of a Zulu speech reception threshold test for Zulu first language speakers in KwaZulu Natal. South African Journal of Communication Disorders, 54, 111-122.

Powell, C. (2002). The Delphi technique: Myths and realities. Methodological Issues in Nursing Research, 41, 376-382.

Schmidt von Wühlisch, F., \& Pascoe, M. (2010). Maximising health literacy and client recall of clinical information: An exploratory study of clients and speech language pathologists. South African Journal of Communication Disorders, 57, 22-32.

Shepard, N.T. (2007). Dizziness and balance disorders: the role of the history and laboratory studies in diagnosis and management. The ASHA Leader. Retrieved on 23 August 2011 from http://www.asha. org/Publications/leader/2007/070529/f070529a.html

South Africa Info. Afrikaans. Retrieved on 23 August 2011 from http://www.southafrica.info/about/ people/language/html

Statistics South Africa (2004). Provincial Profile 2004, Western Cape. Retrieved on 4 January 2009 from http://www.statssa.gov.za

Tschan, R., Wiltink, J., Best, C., Bense, S., Dieterich, M., Beutel, M.E., et al. (2008). Validation of the German version of the Vertigo Symptom Scale (VSS) in patients with organic or somatoform dizzines and healthy controls. Journal of Neurology, 255, 1168-1175.

Webster, K., Cella, D., \& Yost, K. (2003). The Functional Assessment of Chronic Illness Therapy (FACIT) measurement system; Properties, applications and interpretation. Health and Quality of Life Outcomes. Retrieved on 23 August 2011 from www.hqlo.com/content/pdf/1477-7525-1-79.pdf

Wiltink, J., Tschan, R., Michal, M., Subic-Wrana, C., Eckhardt-Henn, A., Dieterich, M., et al. (2009). Dizziness: anxiety, health care utilisation and health behaviour - results from a representative German community survey. Journal of Psychosomatic Research, 66, 417-424.

World Medical Association (2008). Declaration of Helsinki. Retrieved on 17 May 2010 from www.wma. net/en/30publications/10policies/p3/17c.pdf

Yardley, L., Luxon, L.M., \& Haacke, N.P. (1994). A longitudinal study of symptoms, anxiety and subjective well-being in patients with vertigo. Clinical Otolaryngology \& Allied Sciences, 19, 109-116.

Yardley, L., Masson, E., Verschuur, C., Haacke, N., \& Luxon, L. (1992). Symptoms, anxiety and handicap in dizzy patients: Development of the vertigo symptom scale. Journal of Psychosomatic Research, 36, 731-741.

Zwieg, M.H., \& Campbell, G. (1993). Receiver-operating characteristic (ROC) plots: a fundamental evaluation tool in clinical medicine. Clinical Chemistry, 39, 561-577.

\section{Appendix 1. Afrikaanse Vertigo Simptome Skaal \\ Instruksies:}

Omkring asseblief die gepaste nommer om aan te toon ongeveer hoeveel keer jy die volgende simptome, op die lys, ervaar het gedurende die laaste 12 maande (of sedert die duiseligheid begin het, indien jou duiseligheid minder as 'n jaar gelede begin het).

Die verskeidenheid van keuses is:

Nooit

\section{Enkele kere}

(1 - 3 maal'n jaar)
Verskeie kere

(4 - 12 maal 'n jaar)
Redelik gereeld

(gemiddeld, meer as 1 maal per maand
Baie gereeld (gemiddeld, meer as 1 maal per week)

Hoe gereeld gedurende die afgelope 12 maande het jy die volgende simptome gehad:
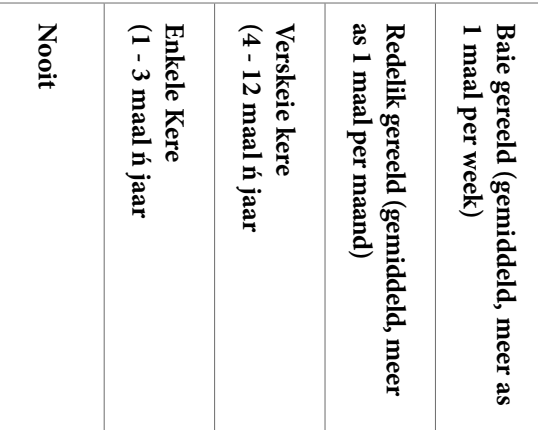

1. 'n Gevoel dat alles draai of in die rondte beweeg, vir 'n tydperk van: [beantwoord asseblief a) tot e)]

a) minder as 2 minute

b) tot en met 20 minute

c) 20 minute tot 1 uur

d) 'n aantal ure

e) meer as 12 ure

2. Pyn in die hart of bors area

3. Warm of koue gloede

4. Onvas op jou voete, so erg dat jy omval

5. Naarheid (siek voel), 'n draai gevoel in die maag

\begin{tabular}{|l|l|l|l|l|}
\hline 0 & 1 & 2 & 3 & 4 \\
\hline 0 & 1 & 2 & 3 & 4 \\
\hline 0 & 1 & 2 & 3 & 4 \\
\hline 0 & 1 & 2 & 3 & 4 \\
\hline 0 & 1 & 2 & 3 & 4 \\
\hline 0 & 1 & 2 & 3 & 4 \\
\hline 0 & 1 & 2 & 3 & 4 \\
\hline 0 & 1 & 2 & 3 & 4 \\
\hline 0 & 1 & 2 & 3 & 4 \\
\hline
\end{tabular}




\begin{tabular}{|c|c|c|c|c|c|}
\hline 6. Spanning/seerheid in jou spiere & 0 & 1 & 2 & 3 & 4 \\
\hline \multicolumn{6}{|c|}{$\begin{array}{l}\text { 7. 'n Gevoel van lighoofdigheid, 'n gevoel van 'swewing' of duiseligheid, vir 'n tydperk van: } \\
\text { [beantwoord asseblief a) tot e)] }\end{array}$} \\
\hline a) minder as 2 minute & 0 & 1 & 2 & 3 & 4 \\
\hline b) tot en met 20 minute & 0 & 1 & 2 & 3 & 4 \\
\hline c) 20 minute tot 1 uur & 0 & 1 & 2 & 3 & 4 \\
\hline d) 'n aantal ure & 0 & 1 & 2 & 3 & 4 \\
\hline e) meer as 12 ure & 0 & 1 & 2 & 3 & 4 \\
\hline 8. Bewerigheid, rillings & 0 & 1 & 2 & 3 & 4 \\
\hline 9. 'n Gevoel van drukking in die oor/ore & 0 & 1 & 2 & 3 & 4 \\
\hline 10. Hartkloppings of -versnellings & 0 & 1 & 2 & 3 & 4 \\
\hline 11. Braking & 0 & 1 & 2 & 3 & 4 \\
\hline 12. 'n Swaar gevoel in die arms of bene & 0 & 1 & 2 & 3 & 4 \\
\hline 13. Visuele versteurings (bv. dofheid, flikkering, kolle voor die oë) & 0 & 1 & 2 & 3 & 4 \\
\hline 14. Hoofpyn of 'n gevoel van drukking in die kop & 0 & 1 & 2 & 3 & 4 \\
\hline 15. Onvermoeë om behoorlik, sonder ondersteuning, te staan of te stap & 0 & 1 & 2 & 3 & 4 \\
\hline 16. Moeilike asemhaling, kortasem & 0 & 1 & 2 & 3 & 4 \\
\hline 17. Verlies van konsentrasie of geheue & 0 & 1 & 2 & 3 & 4 \\
\hline \multicolumn{6}{|c|}{$\begin{array}{l}\text { 18. Onvas op jou voete, besig om balans te verloor, vir 'n tydperk van: [beantwoord asseblief a) } \\
\text { tot e)] }\end{array}$} \\
\hline \multirow{2}{*}{ a) minder as 2 minute } & 0 & 1 & 2 & 3 & 4 \\
\hline & 0 & 1 & 2 & 3 & 4 \\
\hline c) 20 minute tot 1 uur & 0 & 1 & 2 & 3 & 4 \\
\hline d) 'n aantal ure & 0 & 1 & 2 & 3 & 4 \\
\hline e) meer as 12 ure & 0 & 1 & 2 & 3 & 4 \\
\hline 19. Tinteling, prikkeling of lamheid in dele van die liggaam & 0 & 1 & 2 & 3 & 4 \\
\hline 20. Pyne in jou laerug area & 0 & 1 & 2 & 3 & 4 \\
\hline 21. Oormatige sweet & 0 & 1 & 2 & 3 & 4 \\
\hline 22. Voel flou, besig om bewussyn te verloor & 0 & 1 & 2 & 3 & 4 \\
\hline
\end{tabular}

